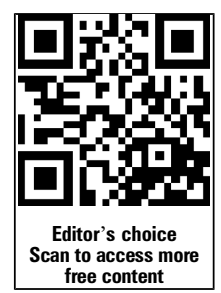

${ }^{1}$ Department of Neurosurgery, Icahn School of Medicine at Mount Sinai, New York, New York, USA ${ }^{2}$ Department of Radiology, Icahn School of Medicine at Mount Sinai, New York, New York, USA

\section{Correspondence to} Dr Aman B Patel, Department of Neurosurgery, Mount Sinai Medical Center, One Gustave L Levy Place, Annenberg Building 8, Box 1136, New York, NY 10029, USA;

aman.patel@mountsinai.org

Received 15 April 2014 Revised 29 April 2014 Accepted 2 May 2014 Published Online First 4 June 2014

\title{
An update to the Raymond-Roy Occlusion Classification of intracranial aneurysms treated with coil embolization
}

\author{
Justin R Mascitelli, ${ }^{1}$ Henry Moyle, ${ }^{1}$ Eric K Oermann, ${ }^{1}$ Maritsa F Polykarpou, ${ }^{1}$ \\ Aanand A Patel, ${ }^{1}$ Amish H Doshi, ${ }^{2}$ Yakov Gologorsky, ${ }^{1}$ Joshua B Bederson, ${ }^{1}$ \\ Aman B Patel ${ }^{1}$
}

\section{ABSTRACT \\ Background The Raymond-Roy Occlusion}

Classification (RROC) is the standard for evaluating

coiled aneurysms (Class I: complete obliteration; Class II: residual neck; Class III: residual aneurysm), but not all Class III aneurysms behave the same over time.

Methods This is a retrospective review of 370 patients with 390 intracranial aneurysms treated with coil embolization. A Modified Raymond-Roy Classification (MRRC), in which Class Illa designates contrast within the coil interstices and Class IIIb contrast along the aneurysm wall, was applied retrospectively.

Results Class IIla aneurysms were more likely to improve to Class I or II than Class IIIb aneurysms (83.34\% vs $14.89 \%, p<0.001)$ and were also more likely than Class II to improve to Class I $(52.78 \%$ vs $16.90 \%, p<0.001)$. Class IIIb aneurysms were more likely to remain incompletely occluded than Class Illa aneurysms $(85.11 \%$ vs $16.67 \%, p<0.001)$. Class Illb aneurysms were larger with wider necks while Class IIla aneurysms had higher packing density. Class IIIb aneurysms had a higher retreatment rate (33.87\% vs $6.54 \%, p<0.001)$ and a trend toward higher subsequent rupture rate $(3.23 \%$ vs $0.00 \%$, $\mathrm{p}=0.068$ ).

Conclusions We propose the MRRC to further

differentiate Class III aneurysms into those likely to progress to complete occlusion and those likely to remain incompletely occluded or to worsen. The MRRC has the potential to expand the definition of adequate coil embolization, possibly decrease procedural risk, and help endovascular neurosurgeons predict which patients need closer angiographic follow-up. These findings need to be validated in a prospective study with independent blinded angiographic grading.

\section{INTRODUCTION}

Endovascular coiling is being used increasingly for the treatment of intracranial aneurysms. ${ }^{1}{ }_{2}^{2}$ The Raymond-Roy Occlusion Classification (RROC; also known as the Montreal Scale, Modified Montreal Scale, or the Raymond Montreal Scale) is a widely accepted system for evaluating aneurysm occlusion class ${ }^{3}$ but was not designed to predict recurrence. ${ }^{4}$ In this scheme, Class I is defined as complete obliteration, Class II as residual neck, and Class III as residual aneurysm. It has been shown that Class III aneurysms have a higher propensity to remain incompletely occluded and potentially rebleed. $^{5-7}$ Since only a proportion of Class III aneurysms remain incompletely occluded, however, it would be useful to understand the factors influencing progression to complete occlusion.

Our experience with coil embolization suggests that Class III aneurysms exhibit heterogeneous behavior, with one subset likely to occlude over time and another likely to remain patent or to grow. We propose the Modified Raymond-Roy Classification (MRRC), in which Class IIIa designates contrast opacification within the coil interstices of a residual aneurysm and Class IIIb designates contrast opacification outside the coil interstices, along the residual aneurysm wall (figure 1). We hypothesize that Class IIIa aneurysms progress to occlusion more frequently than Class IIIb aneurysms.

\section{METHODS}

\section{Study design}

This is a retrospective review of patients treated with coil embolization at a single institution. A database containing 424 patients with 499 intracranial aneurysms treated by endovascular techniques from 2003 to 2014 was examined. After excluding atypical aneurysms (eg, fusiform), those that were previously treated, and those that were not treated with coil embolization (eg, flow diversion), the final study population included 370 patients with 390 aneurysms.

\section{Patients, aneurysms, and procedural} characteristics

Subject and aneurysm characteristics were determined by review of subjects' medical charts and angiographic data. The study population was diverse, including both ruptured and unruptured aneurysms and a wide range of aneurysm sizes and locations. Aneurysm size was determined both qualitatively and quantitatively. The qualitative system involved using the maximum dome diameter and is as follows: small: $<10 \mathrm{~mm}$; large: $10-25 \mathrm{~mm}$; and giant: $>25 \mathrm{~mm}$. Posterior communicating artery aneurysms were included in the anterior circulation.

All aneurysm embolizations were performed at a single institution by two interventional neurosurgeons and one interventional neuroradiologist. A variety of coil and stent types were used as well as different degrees of procedural assistance including stand-alone, balloon-assisted, and stent-assisted coiling. 
Figure 1 Modified Raymond-Roy Classification (MRRC). Class I: complete obliteration; Class II: residual neck; Class Illa: residual aneurysm with contrast within coil interstices; Class IIlb: residual aneurysm with contrast along aneurysm wall.

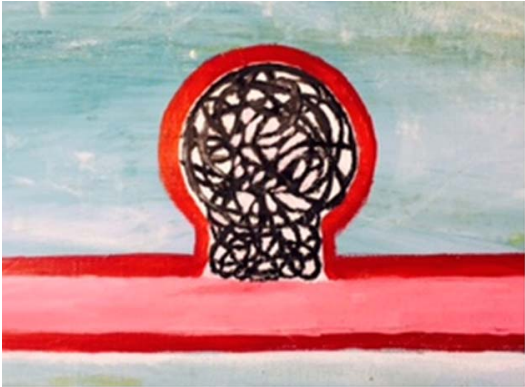

\section{Class I}

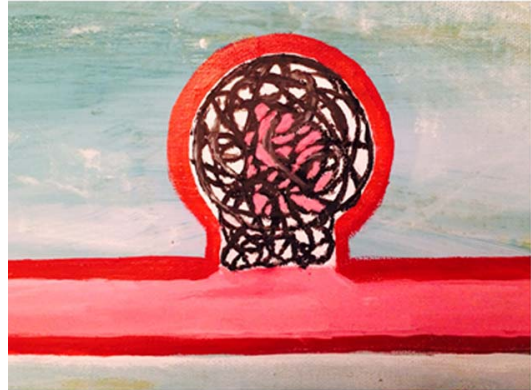

Class IIIa

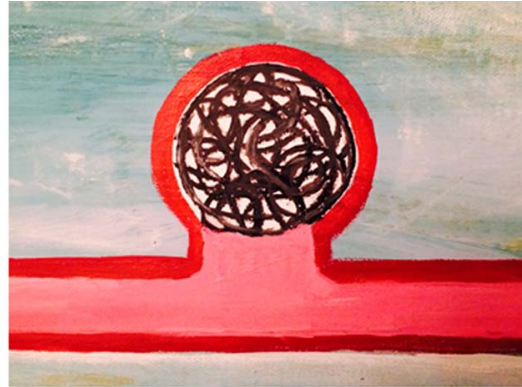

Class II

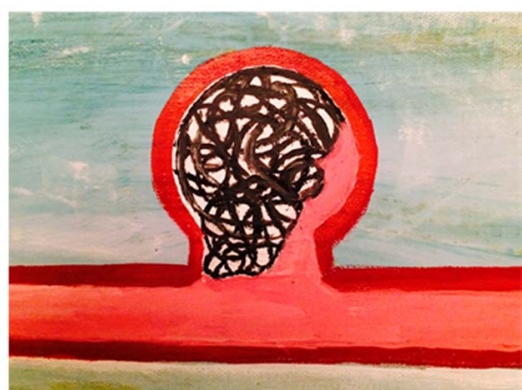

Class IIIb
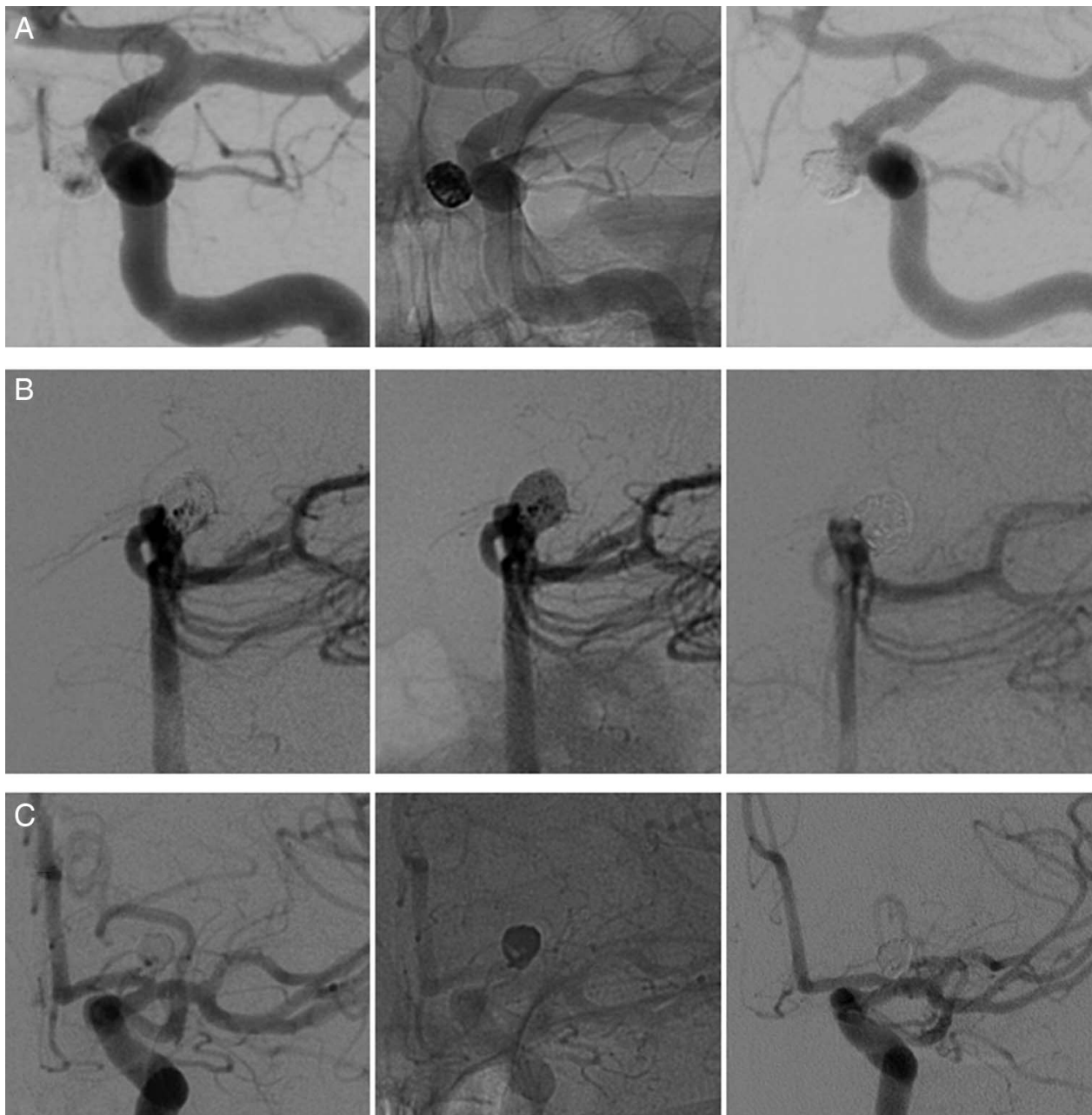

Figure 2 Examples of three aneurysms treated with stand-alone coiling. All three aneurysms were graded as Class IIla because there was contrast within the coil interstices (first column) and because coils opposed the wall of the entire aneurysm (second column). All three aneurysms progressed to occlusion at first follow-up (third column). 

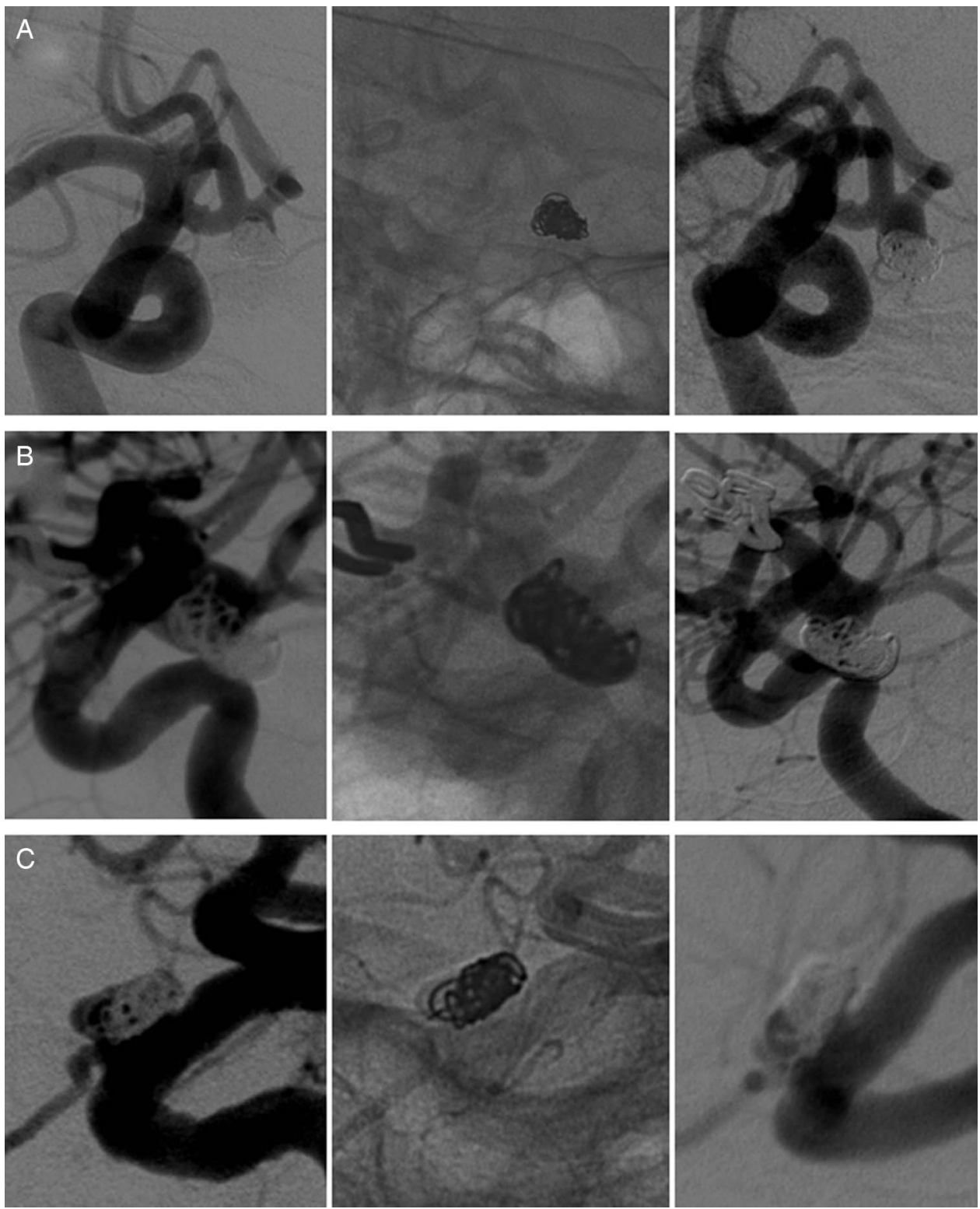

Figure 3 Examples of three aneurysms treated with coil embolization except for the ophthalmic aneurysm (C) that was treated with stent assistance. All three aneurysms were graded as Class IIIb because there was contrast along the aneurysm dome wall (first column) and because there was a gap between the coils and the aneurysm wall (second column). All three aneurysms remained incompletely occluded at first follow-up (third column). The anterior communicating artery $(A)$ and ophthalmic artery aneurysms (C) required retreatment and the posterior communicating artery aneurysm (B) reruptured and required surgical clipping.

\section{Angiographic review}

All initial and follow-up angiograms were reviewed by either interventional neurosurgeon ABP or HM and the MRRC was applied. Although the angiographic review was not blinded, the initial angiogram was always evaluated before the follow-up to reduce bias. The following considerations were taken into account when applying the MRRC:

- All aneurysms were graded in at least two angiographic views.

- Class IIIa or IIIb designation took precedence over the status of the aneurysm neck.

- Flow stasis was not included in the MRRC.

- Any contrast seen within the aneurysm at the end of the procedure was defined as Class III, even if believed to be a result of heparinization or use of antiplatelet therapy.

- Class IIIa designation was only given if coils opposed the wall of the entire aneurysm dome on the unsubtracted view (figure 2). Class IIIb designation was only given if there was a gap between the coils and the aneurysm wall on an unsubtracted view (figure 3).

- Class IIIb aneurysms usually had contrast opacification through a portion of the aneurysm neck with continuation along a portion of the aneurysm wall (figure 3). Occasionally, however, Class IIIb designation was used when the neck was completely occluded (eg, complete coiling of a proximal aneurysm lobule with persistent filling of a distal lobule).

\section{Statistical methods}

The RROC was calculated for each aneurysm at each angiogram as previously discussed. Pretreatment, aneurysm, and treatment variables were assessed for differences between Classes IIIa and IIIb using the Mann-Whitney test or Pearson $\chi^{2}$ test for continuous and categorical variables respectively. Kaplan-Meier 
Table 1 Patient, aneurysm, and procedure data

\begin{tabular}{|c|c|}
\hline \multirow[t]{5}{*}{ General } & Patients: 370 \\
\hline & Aneurysms: 390 \\
\hline & Age: 55.79 years \\
\hline & Women: $75.13 \%(\mathrm{n}=293)$ \\
\hline & Men: $24.87 \%(n=97)$ \\
\hline \multirow[t]{2}{*}{ Rupture status } & Ruptured: $54.87 \%(n=214)$ \\
\hline & Unruptured: $45.13 \%(n=176)$ \\
\hline \multirow[t]{5}{*}{ Aneurysm size } & Small: $79.03 \%(n=309)$ \\
\hline & Large: $20.51 \%(n=80)$ \\
\hline & Giant: $0.26 \%(n=1)$ \\
\hline & Dome volume: $255.13 \mathrm{~mm}^{3}$ \\
\hline & Neck size: 3.80 mmAspect ratio: 2.12 \\
\hline Aneurysm location & $\begin{array}{l}\text { Anterior circulation: } 92.05 \%(n=359) \\
\text { - Cavernous ICA: } 3.08 \%(n=12) \\
\text { Ophthalmic: } 10.51 \%(n=41) \\
\text { Superior hypophyseal: } 6.67 \%(n=26) \\
\text { Posterior communicating: } 24.62 \%(n=96) \\
\text { - Anterior choroidal: } 1.54 \%(n=6) \\
\text { ICA other: } 7.95 \%(n=31) \\
\text { - ICA bifurcation: } 3.85 \%(n=15) \\
\text { - Anterior communicating: } 20.77 \%(n=81) \\
\text { Pericallosal: } 1.28 \%(n=5) \\
\text { - ACA other: } 1.03 \%(n=4) \\
\text { MCA: } 10.77 \%(n=42) \\
\text { Posterior circulation: } 7.95 \%(n=31) \\
\text { Vertebral: } 1.28 \%(n=5) \\
\text { PICA: } 0.77 \%(n=3) \\
\text { Basilar trunk: } 0.51 \%(n=2) \\
\text { B SCA: } 0.77 \%(n=3) \\
\text { Basilar tip: } 3.85 \%(n=15) \\
\text { - PCA: } 0.51 \%(n=2)\end{array}$ \\
\hline Procedure assistance & $\begin{array}{l}\text { Stand-alone: } 61.79 \%(n=241) \\
\text { Balloon: } 10.00 \%(n=39) \\
\text { Stent: } 28.21 \%(n=110)\end{array}$ \\
\hline Coil type & $\begin{array}{l}\text { Galaxy: } 7.69 \%(n=30) \\
\text { GDC: } 15.90 \%(n=62) \\
\text { Hydrocoil: } 0.26 \%(n=1) \\
\text { Matrix: } 7.69 \%(n=30) \\
\text { Orbit: } 33.59 \%(n=131) \\
\text { Penumbra: } 22.05 \%(n=86) \\
\text { Target: } 4.87 \%(n=19) \\
\text { Trufill: } 7.69 \%(n=30) \\
\text { Unknown: } 0.26 \%(n=1) \\
\text { Multiple coil types: } 17.69 \%(n=69)\end{array}$ \\
\hline Stent data & $\begin{array}{l}\text { Enterprise: } 64.55 \%(n=71) \\
\text { Liberty: } 9.09 \%(n=10) \\
\text { Neuroform: } 28.18 \%(n=31) \\
\text { Multiple stents: } 1.82 \%(n=2)\end{array}$ \\
\hline
\end{tabular}

ACA, anterior cerebral artery; ICA, internal carotid artery; MCA, middle cerebral artery; PCA, posterior cerebral artery; PICA, posterior inferior cerebellar artery; SCA, superior cerebellar artery.

curves were constructed to graphically depict time to closure or improvement, and the log rank test was used for subsequent evaluation. All reported $\mathrm{p}$ values are two sided with a standard $\alpha$ set at 0.05 . All averages are the mean average with a SD. All data management and analyses were conducted using SPSS V.20.0 (IBM, Armonk, New York, USA).

Multivariate logistic regression analysis was also performed using SPSS V.20.0. Categorical variables were reclassified as indicator variables, and multivariable models incorporating both the RROC and MRRC were constructed and ORs and $p$ values were calculated for individual predictors within each model.

\section{RESULTS}

Patients, aneurysms, and procedural data

The majority of patients were women $(75.13 \%)$ and the majority of aneurysms were ruptured (54.87\%), small (79.23\%), and in the anterior circulation (92.05\%). Stent and balloon assistance was used in $28.21 \%$ and $10.00 \%$ of cases, respectively. A variety of coil and stent types were used. Aneurysms were treated with bare platinum coils in $92.05 \%$ of cases (table 1).

Compared with Class IIIa aneurysms, Class IIIb aneurysms were larger (636.64 vs $\left.211.25 \mathrm{~mm}^{3}, \mathrm{p}=0.009\right)$ with wider necks (5.04 vs $4.08 \mathrm{~mm}, \mathrm{p}=0.022$ ). Class IIIa aneurysms were treated with higher packing density (PD; $26.18 \%$ vs $20.73 \%$, $\mathrm{p}<0.001)$. Otherwise, no other patient, aneurysm, or procedural characteristics were different between these two groups.

\section{Angiographic data}

Angiographic follow-up was available in $74.48 \%$ of patients at 7.93 months, $35.08 \%$ of patients at 21.54 months, and $17.13 \%$ of patients at 53.56 months. The MRRC was determined immediately after the procedure and at all follow-ups (table 2).

Class IIIa aneurysms were more likely than Class IIIb aneurysms to improve to either Class I $(52.78 \%$ vs $6.38 \%, \mathrm{p}<0.001)$ or to improve to Class II $(30.56 \%$ vs $8.51 \%, p<0.001)$. Class IIIa aneurysms were also more likely than Class II to improve to Class I (52.78\% vs $16.90 \%, \mathrm{p}<0.001$; figures 2 and 4). Class IIIb aneurysms were more likely than Class IIIa aneurysms to remain incompletely occluded $(85.11 \%$ vs $16.67 \%, \mathrm{p}<0.001$; figures 3 and 5). Class IIIa aneurysms were more likely to remain incompletely occluded compared with Class II and I aneurysms (16.67\% vs 3.28\% and $8.45 \%, \mathrm{p}<0.001$; table 3$)$.

Multivariate analysis demonstrated that Class IIIa and IIIb status was independently predictive of progression to occlusion $(p=0.048)$ and recurrence $(p<0.001)$, respectively. In addition, multivariate analysis demonstrated that MRRC Class IIIb status was more predictive of recurrence than RROC Class III (OR 89 vs 21).

\section{Clinical data}

The complication rate in the Class IIIb group compared with the Class IIIa group was not statistically different $(14.29 \%$ vs $6.25 \%, p=0.118)$, nor were the rates of death or permanent disability secondary to the complication $(1.43 \%$ vs $1.79 \%$, $\mathrm{p}=0.165)$. The vasospasm rate was not statistically different between Class IIIa and Class IIIb $(27.08 \%$ vs $12.12 \%$, $\mathrm{p}=0.173)$. The percentage of patients with discharge modified Rankin Scale scores of 3-6 was similar in both groups $(38.89 \%$ vs $29.90 \%, p=0.247)$. There were more retreatments in the Class IIIb group $(33.87 \%$ vs $6.54 \%, \mathrm{p}<0.001)$. There was a trend toward more post-treatment ruptures in the Class IIIb group but this did not reach statistical significance $(3.23 \%$ vs $0.00 \%, p=0.068$; table 4).

\section{DISCUSSION}

Initial angiographic occlusion class is a predictor of aneurysm recurrence and rehemorrhage..$^{5-7}$ Many studies have addressed aneurysm recurrence, but there is less literature examining aneurysms that progress to occlusion. In the current study, a high proportion of coiled aneurysms with residual contrast opacification within the coil interstices at the end of the procedure (Class IIIa) were found to be completely occluded or to exhibit only neck filling at follow-up. This subgroup appeared to have a favorable angiographic outcome in comparison with those aneurysms with contrast opacification outside the coil interstices, along the aneurysm wall (Class IIIb).

There are a few possible explanations for the observations in this study. The prothrombotic environment that coils create ${ }^{8} 9$ are likely to have a greater effect on blood within the coil mass than outside the coil mass. Coil compaction and aneurysm growth are two methods of aneurysm recurrence. ${ }^{10}{ }^{11}$ Blood 
Neuroimaging

Table 2 Modified Raymond-Roy Classification immediately after procedure and at follow-up

A.

First follow-up occlusion class (7.92 months)

\begin{tabular}{|c|c|c|c|c|c|c|}
\hline & & \\
\hline & & I & II & IIla & IIlb & Total \\
\hline \multirow[t]{5}{*}{ Initial occlusion class } & I & $77.05 \%(47)$ & $19.67 \%(12)$ & $0.00 \%(0)$ & $3.28 \%$ (2) & 61 \\
\hline & ॥ & $16.90 \%(12)$ & $74.65 \%(53)$ & $0.00 \%(0)$ & $8.45 \%(6)$ & 71 \\
\hline & Illa & $52.78 \%(38)$ & $30.56 \%(22)$ & $8.33 \%(6)$ & $8.33 \%(6)$ & 72 \\
\hline & Illb & $6.38 \%(3)$ & $8.51 \%(4)$ & $4.26 \%(2)$ & $80.85 \%$ (38) & 47 \\
\hline & Total & 100 & 91 & 8 & 52 & 251 \\
\hline
\end{tabular}

B.

\begin{tabular}{|c|c|c|c|c|c|c|}
\hline & & \multicolumn{5}{|c|}{ Second follow-up occlusion class (21.54 months) } \\
\hline & & $\mathbf{I}$ & II & IIla & IIlb & Total \\
\hline \multirow[t]{5}{*}{ Initial occlusion class } & 1 & $81.08 \%$ (30) & $18.92 \%(7)$ & $0.00 \%(0)$ & $0.00 \%(0)$ & 37 \\
\hline & ॥ & $21.95 \%$ (9) & $73.17 \%(30)$ & $0.00 \%(0)$ & $4.88 \%$ (2) & 41 \\
\hline & Illa & $61.76 \%(21)$ & $32.35 \%(11)$ & $5.88 \%(2)$ & $0.00 \%(0)$ & 34 \\
\hline & $\| l l b$ & $0.00 \%(0)$ & $13.33 \%(2)$ & $6.67 \%(1)$ & $80.00 \%$ (12) & 15 \\
\hline & Total & 60 & 50 & 3 & 14 & 127 \\
\hline
\end{tabular}

along the wall of a Class IIIb aneurysm may promote coil compaction and/or lead to increased wall stress causing aneurysm growth. There is evidence that the mechanism of aneurysm occlusion following coil embolization involves remodeling/ healing of the blood vessel wall along the aneurysm neck. ${ }^{12} 13$ Class IIIb aneurysms usually have an area in the aneurysm neck without coils that can be potentiated by the inflow jet over time and prevent neck healing. An experimental model designed to simulate Class IIIa and IIIb aneurysms is needed to determine the exact mechanism by which these aneurysms either progress to occlusion or recur.

It is not surprising that the Class IIIb group had larger aneurysms with wider necks. These two features inherently make circumferential packing of the entire aneurysm with coils more difficult. It is also not surprising that PD was lower in the Class IIIb group, as low PD has been associated with recurrence in previous studies. ${ }^{14-19}$ It is important to note, however, that the predictive nature of the MRRC was maintained in a multivariate model that removed the influence of aneurysm size, neck size, and PD. In addition, the multivariate model demonstrated that the MRRC was able to predict recurrence better than the standard RROC model.

The two groups had similar clinical courses except that the Class IIIb group had more retreatments and a trend toward more post-treatment ruptures, which are two sources of morbidity for this patient population. This is an important finding because it suggests that the MRRC has an angiographic and also a clinical impact.

There have been previous efforts to augment the RROC. In 2007, Deshaies et al ${ }^{20}$ evaluated 64 patients with 67 aneurysms treated with Hydrocoils. The initial RROC was Class I in 43\%, Class II in 35\%, and Class III in 22\%. In this paper, the patients were stratified by size and the authors looked directly at aneurysm recurrence and improvement in RROC class. They found

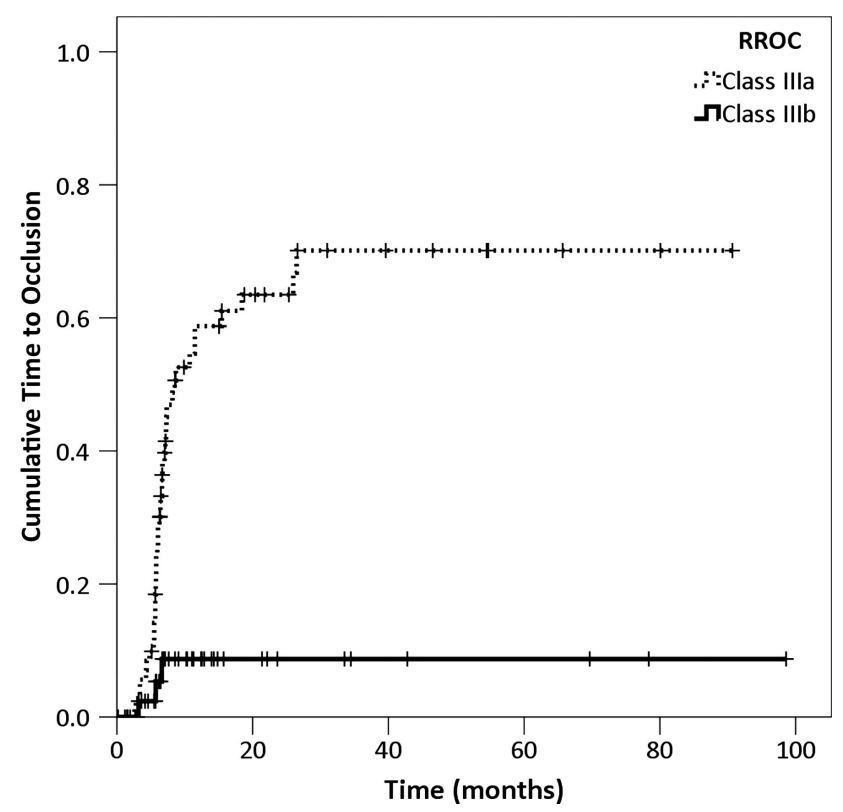

Figure 4 Kaplan-Meier curve demonstrating progression to occlusion over time for Class IIIa and IIlb aneurysms.

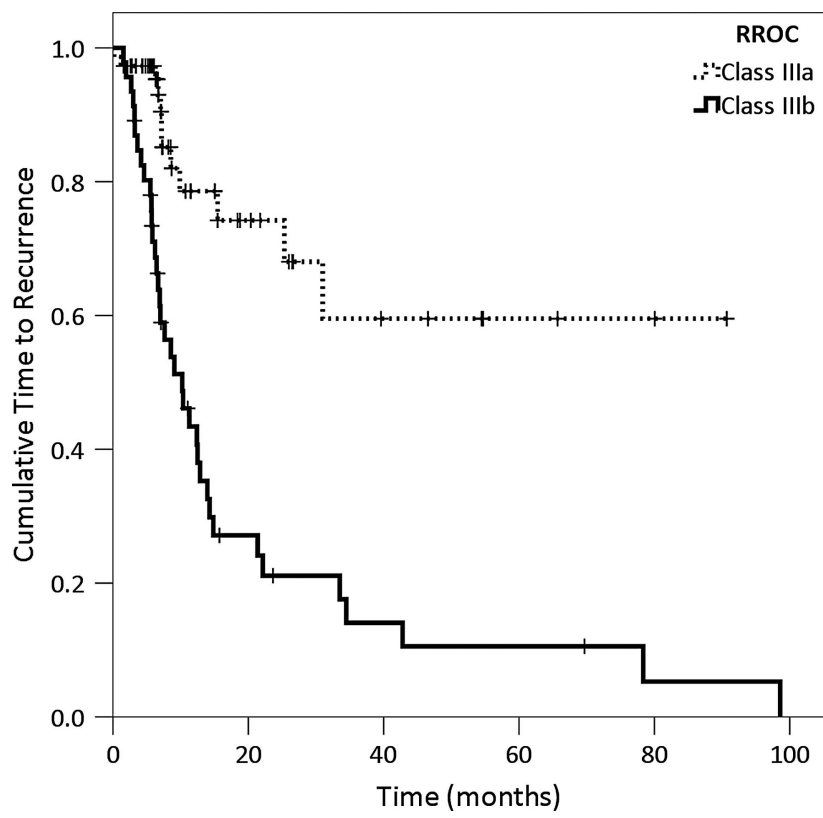

Figure 5 Kaplan-Meier curve demonstrating recurrence over time for Class IIIa and IIIb aneurysms. 
that three large and three very large aneurysms initially designated as Class III ultimately improved to Class I. In the discussion, the authors claimed that incompletely treated aneurysms with stasis of the contrast material in the neck or dome tended to improve whereas those with contrast flow in the neck or dome recurred. Taking these observations into account, the authors went on to develop their own five-point aneurysm embolization grade (AEG) to help predict recurrence.

In 2012, Singla $e t a l^{21}$ reported an internal validity study to evaluate the AEG described above. In this system, AEG A designates no filling of the aneurysm neck or dome, AEG B contrast stasis in the neck and no filling of the dome, AEG C contrast stasis in the neck and dome, AEG D contrast flow in the neck and no filling of the dome, and AEG E contrast flow in the neck and dome. They found that AEG A had significantly better follow-up than all other groups and that the contrast stasis group also had significantly better follow-up than the contrast flow group. They also found that only the RROC Class I designation could be used to predict follow-up durability, and that there was no significant difference between RROC Classes II and III in their predictive value. Stent assistance did not have an effect on initial or long-term durability. The authors favored the AEG system over the RROC system because of its ability to account for hemodynamic flow within the aneurysm neck and dome. While the AEG system accounts for contrast stasis, it does not account for contrast location within the aneurysm dome as is the case with the MRRC.

Stent assistance has been investigated in its ability to promote progression to occlusion. In 2011, Lawson $e t a^{22}$ investigated the capability of stent assistance to augment the progression from incomplete occlusion (Class II or III) to complete occlusion (Class 1). Of 109 patients available for angiographic follow-up, 33 (89\%) in the stented group and 29 (40\%) in the unstented group progressed from either Class II or III to Class I. The authors concluded that stent-assisted coiling promotes a progression to occlusion and complete thrombosis of incompletely coiled aneurysms via a flow remodeling effect. This phenomenon has also been observed in other studies of stent-assisted coiling. ${ }^{23}{ }^{24}$ Interestingly, stent assistance was not identified as an independent factor that promotes progression to occlusion in our study.

In 2013, Abdihalim et $a l^{25}$ investigated contrast stasis as a factor that predicts progression to occlusion. Forty-four patients were identified as having contrast stasis at the end of embolization. Of the patients who underwent follow-up angiography, 21 patients had spontaneous thrombosis of the aneurysm. Size of the contrast stasis $(p=0.02)$ was the only statistically significant factor that influenced this trend. Dome to neck ratio $>2$
Table 4 Clinical data

\begin{tabular}{llll}
\hline & Class IIla & Class IIIb & $\begin{array}{l}\mathbf{p} \\
\text { Value }\end{array}$ \\
\hline Complications & $6.25 \%(7)$ & $\begin{array}{l}14.29 \% \\
(10)\end{array}$ & 0.118 \\
$\begin{array}{l}\text { Death or permanent deficit from } \\
\text { complication }\end{array}$ & $1.79 \%(2)$ & $1.43 \%(1)$ & 0.165 \\
$\begin{array}{l}\text { Vasospasm } \\
\text { Discharge mRS 3-6 }\end{array}$ & $\begin{array}{l}27.08 \% \\
(13)\end{array}$ & $12.12 \%(4)$ & 0.173 \\
Retreatment & $\begin{array}{l}29.90 \% \\
(29)\end{array}$ & $\begin{array}{l}38.89 \% \\
(21)\end{array}$ & 0.247 \\
Post-treatment rupture & $6.54 \%(7)$ & $\begin{array}{l}33.87 \% \\
(21)\end{array}$ & $<0.001$ \\
\hline mRS, modified Rankin Scale. & $0.00 \%(0)$ & $3.23 \%(2)$ & 0.068 \\
\hline
\end{tabular}

$(\mathrm{p}=0.16)$ and washout on the initial angiogram $(\mathrm{p}=0.16)$ only approached statistical significance.

Finally, the knowledge that a Class IIIa result following the procedure is safe and frequently has a favorable progression over time could potentially increase the safety profile of the procedure. Aspiring to always achieve a Class I result requires increased fluoroscopic time, increased number of coils placed, and increased attempts at catheterizing the aneurysm (if the catheter were to herniate out of the aneurysm during the procedure). Increased angiographic time ${ }^{26}$ and prolonged attempts at achieving complete aneurysm occlusion ${ }^{27}$ have been shown to be associated with an increased ischemic stroke rate.

On the other hand, a Class IIIa result can be achieved more quickly, with fewer coils, and frequently progresses to a Class I or II result at follow-up. Certainly, a Class I result is the most desirable and provides the most protection against recanalization (as seen in our results) or rerupture. It is important to know, however, that, in the vast majority of cases, a Class IIIa result can also provide a safe and stable outcome. Fortunately, none of our Class IIIa aneurysms presented with rerupture.

We understand that this study is limited by its retrospective nature, the subjective nature of the RROC/MRRC, and the lack of an independent blinded angiographic review. Certainly many occlusion grades are debatable, and it has been shown that there is frequently disagreement between observers when using these grading scales (especially as the number of categories in the scale increases). ${ }^{28}{ }^{29}$ Some authors have advocated replacing the RROC system with computerized grading scales due to the subjective nature of the classification and interobserver variation. $^{30} 31$ In addition, the MRRC does not differentiate

Table 3 Angiographic follow-up

\begin{tabular}{|c|c|c|c|c|}
\hline \multicolumn{5}{|l|}{ A. } \\
\hline & Class IIla & & Class IIIb & p Value \\
\hline Improved to Class I or II & $83.34 \%(60)$ & & $14.89 \%(7)$ & $<0.001$ \\
\hline Remained Class III & $16.67 \%(12)$ & & $85.11 \%(40)$ & $<0.001$ \\
\hline \multicolumn{5}{|l|}{ B. } \\
\hline & Class I & Class II & Class IIla & $\mathrm{p}$ Value \\
\hline Improved to Class I & - & $16.90 \%(12)$ & $52.78 \%(38)$ & $<0.001$ \\
\hline Worsened to or remained Class III & $3.28 \%(2)$ & $8.45 \%(6)$ & $16.67 \%(12)$ & $<0.001$ \\
\hline
\end{tabular}


between contrast flow and stasis, which may also be an important factor. ${ }^{141519}$

\section{CONCLUSIONS}

We propose the MRRC to further differentiate Class III aneurysms into those likely to progress to complete occlusion and those likely to remain incompletely occluded or to worsen. The MRRC has the potential to expand the definition of adequate coil embolization, reduce procedural risk, and stratify patients with residual aneurysms into those at higher and lower risk for recurrence. Understanding this phenomenon should prove useful to other interventional neurosurgeons. These findings need to be validated in a prospective study with angiographic grading by an independent blinded neuroradiologist or interventional neurosurgeon.

Acknowledgements We would like to acknowledge Margaret Panzer for her artwork in figure 1 and Michael Chary for his assistance with statistics.

Contributors All authors had integral participation in the study. AAP, JRM, HM, $A D, J B B$ and $Y G$ were involved in conception of the project. JRM, MFP and AAP performed the data collection. $A B P, H M, A D$ and JRM performed the angiographic review. EKO performed the statistical analysis and figure/table presentation. All authors were involved in manuscript preparation.

\section{Competing interests None.}

Ethics approval Ethics approval was obtained from the Institutional Review Board.

Provenance and peer review Not commissioned; externally peer reviewed.

Data sharing statement We are not participating in data sharing.

\section{REFERENCES}

1 Molyneux AJ, Kerr RS, Yu LM, et al.; International Subarachnoid Aneurysm Trial (ISAT) Collaborative Group. International subarachnoid aneurysm trial (ISAT) of neurosurgical clipping versus endovascular coiling in 2143 patients with ruptured intracranial aneurysms: a randomised comparison of effects on survival, dependency, seizures, rebleeding, subgroups, and aneurysm occlusion. Lancet 2005;366:809-17.

2 Lin N, Cahill KS, Frerichs KU, et al. Treatment of ruptured and unruptured cerebral aneurysms in the USA: a paradigm shift. J Neurointerv Surg 2012;4:182-9.

3 Roy D, Milot G, Raymond J. Endovascular treatment of unruptured aneurysms. Stroke 2001;32:1998-2004.

4 Raymond J, Guilbert F, Weill A, et al. Long-term angiographic recurrences after selective endovascular treatment of aneurysms with detachable coils. Stroke 2003;34:1398-403.

5 Raymond J, Roy D. Safety and efficacy of endovascular treatment of acutely ruptured aneurysms. Neurosurgery 1997:41:1235-44.

6 Johnston S, Dowd C, Higashida R, et al. Predictors of rehemorrhage after treatment of ruptured intracranial aneurysms: the Cerebral Aneurysm Re-rupture After Treatment (CARAT) Study. Stroke 2008;39:120-5.

7 Ries T, Siemonsen S, Thomalla G, et al. Long-term follow-up of cerebral aneurysms after endovascular therapy prediction and outcome of retreatment. AJNR Am J Neuroradiol 2007:28:1755-61.

8 Kallmes DF, Helm GA, Hudson SB, et al. Histologic evaluation of platinum coil embolization in an aneurysm model in rabbits. Radiology 1999;213:217-22.

9 Lee D, Yuki I, Murayama Y, et al. Thrombus organization and healing in the swine experimental aneurysm model. Part I. A histological and molecular analysis. J Neurosurg 2007;107:94-108.

10 Abdihalim M, Watanabe M, Chaudhry SA, et al. Are coil compaction and aneurysmal growth two distinct etiologies leading to recurrence following endovascular treatment of intracranial aneurysm? J Neuroimaging 2014;24:171-5.
11 Hasan DM, Nadareyshvili Al, Hoppe AL, et al. Cerebral aneurysm sac growth as the etiology of recurrence after successful coil embolization. Stroke 2012; 43:866-8.

12 Tenjin H, Fushiki S, Nakahara Y, et al. Effect of Guglielmi detachable coils on experimental carotid artery aneurysms in primates. Stroke 1995;26:2075-80.

13 Raymond J, Darsaut T, Salazkin I, et al. Mechanisms of occlusion and recanalization in canine carotid bifurcation aneurysms embolized with platinum coils: an alternative concept. AJNR Am J Neuroradiol 2008;29:745-52.

14 Grunwald IQ, Balami JS, Weber D, et al. Different factors influence recanalisation rate after coiling in ruptured and unruptured intracranial aneurysms. CNS Neurol Disord Drug Targets 2013;12:228-32.

15 Leng $B$, Zheng $Y$, Ren J, et al. Endovascular treatment of intracranial aneurysms with detachable coils: correlation between aneurysm volume, packing, and angiographic recurrence. J Neurointerv Surg 2014;6:595-9.

16 Kawanabe $Y$, Sadato A, Taki W, et al. Endovascular occlusion of intracranial aneurysms with Guglielmi detachable coils: correlation between coil packing density and coil compaction. Acta Neurochir (Wien) 2001;143(5):451-5.

17 Sluzewski M, van Rooij WJ, Slob MJ, et al. Relation between aneurysm volume, packing, and compaction in 145 cerebral aneurysms treated with coils. Radiology 2004;231:653-8

18 Wakhloo AK, Gounis MJ, Sandhu JS, et al. Complex-shaped platinum coils for brain aneurysms: higher packing density, improved biomechanical stability, and midterm angiographic outcome. AJNR Am J Neuroradiol 2007;28:1395-400.

19 Otani T, Nakamura M, Fujinaka T, et al. Computational fluid dynamics of blood flow in coil-embolized aneurysms: effect of packing density on flow stagnation in an idealized geometry. Med Biol Eng Comput 2013;51:901-10.

20 Deshaies EM, Adamo MA, Boulos AS. A prospective single-center analysis of the safety and efficacy of the hydrocoil embolization system for the treatment of intracranial aneurysms. J Neurosurg 2007;106:226-33.

21 Singla A, Villwock MR, Jacobsen W, et al. Aneurysm embolization grade: a predictive tool for aneurysm recurrence after coil embolization. Acta Neurochir (Wien) 2013;155:231-6.

22 Lawson MF, Newman WC, Chi YY, et al. Stent-associated flow remodeling causes further occlusion of incompletely coiled aneurysms. Neurosurgery 2011;69:598-603; discussion 603-4.

23 Santillan A, Greenberg E, Patsalides A, et al. Long-term clinical and angiographic results of Neuroform stent-assisted coil embolization in wide-necked intracranial aneurysms. Neurosurgery 2012;70:1232-7.

24 Hwang G, Park H, Bang JS, et al. Comparison of 2-year angiographic outcomes of stent- and nonstent-assisted coil embolization in unruptured aneurysms with an unfavorable configuration for coiling. AJNR Am J Neuroradiol 2011; 32:1707-10

25 Abdihalim MM, Chaudry SA, Tariq N, et al. The natural history of "contrast stasis" within aneurysm after embolization. J Vasc Interv Neurol 2013;5:14-21.

26 Willinsky RA, Taylor SM, TerBrugge K, et al. Neurologic complications of cerebral angiography: prospective analysis of 2,899 procedures and review of the literature. Radiology 2003;227:522-8.

27 Bradac GB, Bergui M, Stura G, et al. Periprocedural morbidity and mortality by endovascular treatment of cerebral aneurysms with GDC: a retrospective 12-year experience of a single center. Neurosurg Rev 2007;30(2):117-25; discussion 125-6.

28 Cloft HJ, Kaufmann T, Kallmes DF. Observer agreement in the assessment of endovascular aneurysm therapy and aneurysm recurrence. AJNR Am J Neuroradiol 2007;28:497-500.

29 Tollard É, Darsaut TE, Bing F, et al. Outcomes of endovascular treatments of aneurysms: observer variability and implications for interpreting case series and planning randomized trials. AJNR Am J Neuroradiol. 2012;33:626-31.

30 Sherif C, Gruber A, Schuster E, et al. Computerized occlusion rating: a superior predictor of aneurysm rebleeding for ruptured embolized aneurysms. AJNR Am J Neuroradiol 2012;33:1481-7.

31 Milavec $H$, Gruber A, Schuster $E$, et al. Computerized occlusion rating of embolized ruptured intracranial aneurysms: relation to intra- and postinterventional aneurysm rehemorrhage. Acta Neurochir Supp/ 2013;115:119-23. 